\title{
FAKTOR-FAKTOR RESIKO STROKE ISKEMIK PADA PASIEN DI RUMAH SAKIT PTPN II BANGKATAN BINJAI TAHUN 2016
}

\author{
Risk Factors of Iskemic Stroke in Patients in PTPN II \\ Bangkatan Binjai Hospital 2016
}

\author{
Sri Wahyuni ${ }^{1}$ \\ ${ }^{1}$ Dosen Akademi Keperawatan Sehat Binjai \\ E-mail: sriwahyunimiko@yahoo.co.id
}

\begin{abstract}
Abstrak
Stroke iskemik merupakan stroke yang hampir $25 \%$ disebabkan oleh sumbatan bekuan darah, penyempitan sebuah arteri atau beberapa arteri yang mengarah ke otak atau embolus (kotoran) yang terlepas dari jantung atau arteri estrakrani (arteri yang berada diluar tengkorak) yang menyebabkan sumbatan disatu atau beberapa arteri intrakrani ( arteri yang berada didalam tengkorak). Tujuan penelitian ini untuk mengetahui faktor-faktor resiko stroke iskemik di RS PTPN II Bangkatan Binjai. Jenis penelitian ini bersifat deskriptif dengan desain cross sectional. Populasi dalam penelitian ini adalah seluruh pasien stroke iskemik dengan jumlah sampel 42 orang. Hasil penelitian menunjukkan bahwa mayoritas pasien berusia 50-55 tahun yaitu sebanyak 15 orang (36\%), mayoritas pasien berjenis kelamin laki-laki yaitu sebanyak 24 orang (57\%), mayoritas pasien berpendidikan SD yaitu sebanyak 16 orang (38\%), mayoritas pekerjaan pasien adalah bekerja sebagai PNS yaitu sebanyak 14 orang ( 33\%). Stroke iskemik akibat hipertensi yaitu sebanyak 32 orang (76\%), stroke iskemik akibat merokok sebanyak 22 orang $(52 \%)$, stroke iskemik akibat diabetes sebanyak 23 orang $(55 \%)$, stroke iskemik akibat kolesterol sebanyak 21 orang $(50 \%)$. Penderita stroke iskemik harus mengetahui lebih jauh apa yang dimaksud dengan pencegahan dan penanganan yang diperoleh dari tim medis. Diharapkan kepada penderita stroke iskemik agar mengontrol hal-hal yang mempengaruhi atau mendorong terjadinya stroke iskemik. Diharapkan agar tenaga medis dapat memberikan penjelasan dan penyuluhan kepada penderita stroke iskemik tentang faktor-faktor resiko stroke iskemik beserta pencegahannya.
\end{abstract}

Kata Kunci : Faktor Resiko, Stroke Iskemik

\begin{abstract}
Ischemic stroke is a stroke that is almost $25 \%$ caused by blockage of a blood clot, narrowing of an artery or some arteries that lead to the brain or embolus (feces) that is released from the heart or an estrhetic artery (an artery outside the skull) that causes a single or multiple arteries intracran (arteries inside the skull). The purpose of this study was to determine the risk factors for ischemic stroke in PT Departure II Bangkat Binjai Hospital. This type of research is descriptive with a cross sectional design. The population in this study were all ischemic stroke patients with a sample of 42 people. The results showed that the majority of patients aged 50-55 years as many as 15 people $(36 \%)$, the majority of patients were male as many as 24 people $(57 \%)$, the majority of patients had elementary education as many as 16 people (38\%), the majority the work of patients is working as civil servants as many as 14 people (33\%). Ischemic stroke due to hypertension as many as 32 people $(76 \%)$, ischemic stroke due to smoking as many as 22 people $(52 \%)$, ischemic stroke due to diabetes as many as 23 people $(55 \%)$, ischemic stroke due to cholesterol as many as 21 people (50\%). Ischemic stroke sufferers must know more about what is meant by prevention and treatment obtained from the medical team. It is expected that ischemic stroke patients will control things that affect or encourage ischemic stroke. It is expected that medical personnel can provide an explanation and counseling to ischemic stroke patients about ischemic stroke risk factors and their prevention
\end{abstract}

Keywords: Risk Factors, Ischemic Stroke

\section{PENDAHULUAN}

Stroke adalah suatu tanda klinis yang berkembang cepat akibat gangguan otak fokal (global) dengan gejala-gejala yang berlangsung selama 24 jam atau lebih dan dapat menyebabkan kematian tanpa adanya penyebab lain yang jelas selain vaskuler (WHO, 2005). Stroke merupakan penyakit utama yang menyebabkan kematian diseluruh dunia dan penyebab ketiga kematian di 
Amerika Serikat, setelah penyakit jantung dan semua kanker. Meskipun terjadi perbaikan di tingkat kematian stroke dipertengahan abad ke-20, stroke terjadi pada lebih dari 700.000 orang per tahun dan menyebabkan kematian 150.000. Akhir-akhir ini terjadi kemajuan dalam pengetahuan tentang patofisiologi stroke yang memberikan rekomendasi berdasarkan bukti pengelolaan pasien stroke (Dipiro, 2005).

Setiap 1.000 orang 8 orang diantaranya terkena stroke.Di Indonesia stroke iskemik merupakan masalah kesehatan dan perlu mendapat perhatian khusus. Stroke merupakan penyebab utama kematian pada semua umur, dengan proporsi $15,4 \%$ (depkes.go.id) Berdasarkan usia dan jenis kelamin, tingkat kematian yang disebabkan stroke iskemik di Indonesia adalah 99/100.000, sedangkan tingkat kecacatannya adalah 685/100.000. Prevalensi stroke secara keseluruhan di Indonesia adalah $0,8 \%$ Usia rata dan stroke iskemik pada 80,1 \% (Kusuma,2009).

Berdasarkan Asosiasi Jantung di Amerika pada tahun 2006, dari semua kasus stroke iskemik, presentase untuk stroke iskemik adalah $88 \%$. Masalah stroke di Indonesia semakin penting dan mendesak karena kini jumlah penderita di Indonesia adalah terbanyak dan menduduki urutan kedua pada usia diatas 60 tahun dan urutan kelima pada usia 15-59 tahun (Yastroki, 2012).

Stroke merupakan sindrom klinis akibat gangguan pembuluh darah otak, timbul mendadak dan biasanya mengenai penderita usia 45-80 tahun. Umumnya laki-laki sedikit lebih sering terkena dari pada perempuan. Biasa nya tidak ada gejala-gejala prodromo atau gejala dini, dan muncul begitu mendadak. Secara defenisi WHO (World Health Organization) menetapkan bahwa deficit neurologic yang timbul semata-mata karena penyakit pembuluh darah otak dan bukan oleh sebab yang lain.

Berdasarkan Riset Kesehatan Dasar (Riskedas) Nasional tahun 2013, prevalensi stroke di Indonesia berdasarkan diagnosis tenaga kesehatan sebesar tujuh per mil dan yang terdiagnosis oleh tenaga kesehatan (nakes) atau gejala sebesar 12,1 per mil. Jadi, sebanyak $57,9 \%$ penyakit stroke telah terdiagnosis oleh nakes, prevalensi stroke berdasarkan diagnosis nakes tertinggi di DKI Jakarta masing-masing 9,7 per mil. Prevalensi stroke berdasarkan diagnosis nakes sedangkan Sumatera Barat sebesar 12,2 per mil, dan di Rumah Sakit PTPN II Bangkatan sekitar $\leq 6,5 \%$.

Stroke iskemik merupakan penyakit serebrovascular yang semakin sering dijumpai. Di Amerika Serikat, stroke merupakan penyebab kematian terbesar ketiga, dan menyebabkan kematian, stroke juga merupakn penyebab utama kecacatan dan penyebab seseorang dirawat dirumah sakit dalam waktu lama. Disamping itu stroke merupakan penyebab tersering kedua kepikunan setelah penyakit Alzheimer. Pada tahun 2000, penderita stroke iskemik di Amerika Serikat menghabiskan biaya sebesar 30 milyar dolar Amerika untuk perawatan

\section{METODE PENELITIAN}

Jenis penelitian ini bersifat deskriptif dengan tujuan untuk mengetahui faktor-faktor resiko terjadinya stroke iskemik pada pasien di Rumah Sakit PTPN II Bangkatan Binjai 2016. Penelitian ini menggunakan desain cross sectional yaitu rancangan penelitian yang pengukurannya atau pengamatannya dilakukan secara simultan pada suatu saat (sekali waktu) (Arikunto, 2013). Penelitian ini dilakukan mulai dari bulan Januari sampai dengan Mei 2016. Populasi dalam penelitian ini adalah seluruh pasien stroke iskemik di Rumah Sakit PTPN II Bangkatan Binjai sebanyak 42 orang. Teknik pengambilan sampel dalam penelitian ini menggunakan total sampling yaitu seluruh populasi dijadikan sampel karena jumlah populasi <100. Berdasarkan teknik sampel tersebut maka jumlah sampel dalam penelitian ini adalah 42 orang (Hidayat, 2013). Pengumpulan data menggunakan kuesioner. Untuk mengukur data dalam penelitian ini digunakan skala guttman yaitu skala yang bersifat tegas dan konsisten dengan memberikan jawaban Ya dan Tidak, apabila skor benar nilainya 1 dan apabila salah nilainya 0 . Hasil persentase dari pemberian skor dari penelitian di interprestasikan dengan mengunakan kriteria yaitu dominan bila pertanyaan dijawab oleh responden $\geq 50$, dan 
tidak dominan bila pertanyaan dijawab benar oleh responden $<50 \%$.

HASIL PENELITIAN

Faktor-Faktor Resiko Stroke Iskemik
Faktor-faktor resiko pasien stroke iskemik pasien di Rumah Sakit PTPN II Bangkatan Binjai dapat dilihat pada tabeltabel ini.:

Tabel 1. Distribusi Responden Berdasarkan Faktor Resiko Stroke Iskemik Yang Dapat Dikendalikan (Hipertensi)

\begin{tabular}{cccc}
\hline No & Hipertensi & Frekuensi & \% \\
\hline 1 & Dominan & 32 & 76 \\
2 & Tidak Dominan & 10 & 24 \\
\hline & Total & $\mathbf{4 2}$ & $\mathbf{1 0 0}$ \\
\hline
\end{tabular}

Berdasarkan tabel di atas dapat diketahui bahwa terdapat 32 orang $(76 \%)$ menderita stroke iskemik akibat

hipertensi, dan faktor lain sebanyak 10 orang $(24 \%)$

Tabel 2. Distribusi Responden Berdasarkan Faktor Resiko Stroke Iskemik Yang Dapat Dikendalikan (Merokok)

\begin{tabular}{cccc}
\hline No & Merokok & Frekuensi & \% \\
\hline 1 & Dominan & 22 & 52 \\
2 & Tidak Dominan & 20 & 48 \\
\hline & Total & $\mathbf{4 2}$ & $\mathbf{1 0 0}$ \\
\hline
\end{tabular}

Berdasarkan tabel di atas dapat diketahui bahwa dari 42 responden yang menderita orang $(52 \%)$ dan faktor lain sebanyak 20 stroke iskemik akibat merokok sebanya 22 orang $(48 \%)$.

Tabel 3. Distribusi Responden Berdasarkan Faktor Resiko Stroke Iskemik Yang Tidak Dapat Di Kendalikan (Diabetes).

\begin{tabular}{cccc}
\hline No & Diabetes & Frekuensi & \% \\
\hline 1 & Dominan & 23 & 55 \\
2 & Tidak Dominan & 19 & 45 \\
\hline & Total & $\mathbf{4 2}$ & $\mathbf{1 0 0}$ \\
\hline
\end{tabular}

Berdasarkan tabel di atas dapat penyakit diabetes sebanyak 23 orang diketahui bahwa dari 42 responden $(55 \%)$ dan dari faktor lain $45 \%$ yang menderita stroke iskemik akibat

Tabel 4. Distribusi Responden Berdasarkan Faktor Resiko stroke Iskemik yang Dapat Dikendalikan (Kolesterol)

\begin{tabular}{cccc}
\hline No & Kolestrol & Frekuensi & \% \\
\hline 1 & Dominan & 21 & 50 \\
2 & Tidak Dominan & 21 & 50 \\
\hline
\end{tabular}


Berdasarkan tabel diatas dapat diketahui bahwa dari 42 responden terdapat 21 orang $(50 \%)$ menderita stroke iskemik akibat kolestrol dan akibat faktor lain sebanyak 21 orang (50\%).

\section{PEMBAHASAN}

\section{Faktor - Faktor Resiko Stroke}

\section{Iskemik}

\section{Hipertensi}

Diketahui bahwa dari 42 responden atau $100 \%$ responden terdapat 32 orang (76\%) terkena stroke iskemik yang disebabkan oleh hipertensi, ini membuktikan dengan pedapat (feingin ) bahwa meningkatkan resiko stroke iskemik dan penyakit kardiovaskuler lain berawal pada tekanan darah 115/75 mmHg dan meningkatkan dua kali lipat setiap peningkatan $20 / 10 \mathrm{mmHg}$ orang jelas menderita hipertensi (tekanan stroke sama atau lebih besar dari 90 mmHg akan menyebabkan terkena stroke iskemik.

\section{Merokok}

Diketahui bahwa dari 42 responden atau $100 \%$ responden terdapat 22 orang $(52 \%)$, terkena stroke iskemik yang disebabkan oleh rokok, ini dibuktikan dengan pendapat (mulyatsih), bahwa kebiasaan merokok telah terbukti antara lain dapat mengganggu kemampuan darah untuk meningkatkan oksigen dan merusak relentuhan sel darah, kebiasaan ini akan menjadi penyebab terkena stroke.

\section{Diabetes}

Diketahui bahwa 42 responden atau $100 \%$ responden terdapat 23 orang $(55 \%)$ yang terkena stroke iskemik disebabkan oleh diabetes. Ini dibuktikan dengan pendapat (sutrisno), bahwa penderita diabetes bisa memicu stroke karena kadar gula darah yang tinggi bisa merusak pembuluh darah .

4. Kolestrol

Diketahui bahwa dari 42 responden atau $100 \%$ responden terdapat 21 orang (50\%), yang terkena stroke iskemik disebabkan oleh kolestrol tinggi, ini dibuktikan dengan pendapat (vitahealth), bahwa secara umum peningkatan kolestrol merupakan resiko terjadinya stroke iskemik

\section{KESIMPULAN}

Berdasarkan hasil penelitian, maka dapat disimpulkan bahwa :

1. Mayoritas pasien berusia 50-55 tahun yaitu sebanyak 15 orang (36\%)

2. Mayoritas pasien laki-laki sebanyak 24 orang $(57 \%)$,

3. Mayoritas pasein berpendidikan SD yaitu sebanyak 16 orang (38\%)

4. Mayoritas pasien yang bekerja sebagai PNS yaitu sebanyak 14 orang $(33 \%)$,

5. Faktor resiko stroke iskemik akibat hipertensi sebanyak 32 orang $(76 \%)$

6. Faktor resiko stroke iskemik akibat merokok sebanyak 22 orang (52\%)

7. Faktor resiko stroke iskemik akibat diabetes sebanyak 23 orang (55\%)

8. Faktor resiko stroke iskemik akibat kolestrol sebanyak 21 orang (50\%)

\section{SARAN}

Adapun saran dalam penelitian ini adalah:

1. Penderita stroke iskemik harus mengetahui lebih jauh apa yang dimaksud dengan pencegahan dan penanganan yang diperoleh dari tim medis.

2. Diharapkan kepada penderita stroke iskemik agar mengontrol hal-hal yang mempengaruhi atau mendorong terjadinya stroke iskemik.

3. Diharapkan agar tenaga medis dapat memberikan penjelasan dan penyuluhan kepada penderita stroke iskemik tentang faktor-faktor resiko stroke iskemik dan pencegahannya.

\section{DAFTAR PUSTAKA}

Arikunto, Suharsimi, 2013. Prosedur Penelitian : Suatu Pendekatan Praktek, Jakarta : Rineka Cipta. 
Cole, 2009, Esensial Stroke Untuk Layanan Primer, Jakarta 2011 Fakultas Kedokteran Universitas Indonesia.

David Alway \& John Walden. Departemen Kesehatan Republik Indonesia, 2013. Riset Kesehatan Dasar Indonesia Tahun 2013. Jakarta: Badan Penelitian dan Pengembangan Kesehatan Departemen Kesehatan RI.

Hendra Utama. 2007, Unit Stroke Manajemen Stroke Secara Komprehensif, Jakarta
Hidayat, A. Aziz Alimul, 2013. Metode Penelitian Keperawa-tan dan Teknik Analisis Data, Jakarta : Salemba Medika.

IP. Suiraoka, 2005. Penyakit Degeneratif Mengenal, Mencegah Dan Mengurangi Faktor Resiko 9 Penyakit Degeneratif, sorowajan baru Yogyakart.

Ratna Dewi Pudiastuti. 2013. Penyakitpenyakit mematikan Yogyakarta

Sarif La Ode, 2015. Asuhan Keperawatan Gerontik. Sorowajan baru Yogyakarta. 